\title{
ESCOLA NORMAL RURAL: ESPAÇO DE FORMAÇÃO DE GRUPOS DIRIGENTES
}

\section{RURAL TEACHER EDUCATION SCHOOL: SPACE FOR THE EDUCATION OF MANAGEMENT GROUPS}

Flávia Obino Corrêa Werle*

\begin{abstract}
Resumo: Propõe-se, neste texto, uma discussão acerca da formação do professor para escolas rurais no Rio Grande do Sul, oferecida na década de 1940 a 1970, em nível secundário, sinalizando que, pela qualidade e exigência da proposta curricular, formaram-se dirigentes e lideres para diversos espaços sociais da sociedade brasileira. É um texto síntese que analisa dados levantados por meio de entrevistas com ex-alunos e ex-professores, consulta a documentos, analise curricular de diversas escolas normais rurais do período.
\end{abstract}

Palavras-chave: Formação de professores. Habitus. Educação das elites.

Abstract: This text discusses the education of teachers for rural schools at secondary level offered in Rio Grande do Sul from the decades of 1940 to 1970, highlighting that due to the quality and demands of the curricular proposal, a good number of managers and leaders were trained for various social spaces of the Brazilian society. It is a synthetic text that analyzes data obtained from interviews with former students and teachers, document analysis and from the curricular analysis of various rural teacher education schools of the period studied.

Keywords: Teacher education. Habitus. Education of elites.

Usualmente a escola normal não é tematizada em debates que privilegiam a formação de grupos dirigentes, pois, especialmente ao longo da primeira metade do século $\mathrm{XX}$, era considerada uma instituição de nível complementar ao primário (WERLE, 1997); ou, quando muito, de nível secundário. No caso brasileiro, a formação do professor em nível superior foi apenas exigida nas ultimas décadas do século XX. Se voltarmos nossa atenção para as escolas normais rurais - ENR, não as identificaríamos como instituições de referência para compreender a formação das elites, pois tinham como finalidade explícita as populações rurais. No final do século XIX, os mestres preferiam ensinar em centros urbanos e as políticas públicas propunham pequenas escolas normais nas cidades de segunda classe (ALMEIDA, 1989). Os governantes tinham exigências menores para aulas de zonas rurais, no que se refere à frequência dos alunos, ao preparo dos professores e aos conteúdos a serem ensinados (WERLE, 2004, 2008). Entretanto,

\footnotetext{
* Doutorado em Educação pela Pontifícia Universidade Católica do Rio Grande do Sul e pós-doutora pela Universidade do Minho, Portugal. Professora da Universidade do Vale do Rio dos Sinos. Bolsista produtividade 1B do CNPq. E-mail: <flaviaw2008@gmail.com>.

* Doctor in Education from the Catholic University of Rio Grande do Sul. Postdoctoral from the Minho University, Portugal. Professor at the University of Vale do Rio dos Sinos. Has a scholarship level 1B from CNPq. E-mail: <flaviaw2008@gmail.com>.
} 
analisando documentos de ENR e depoimentos de ex-alunos e ex-professores destes estabelecimentos, este estudo ${ }^{1}$ identifica-os como espaços ativos de formação de elites. Referimo-nos especialmente às ENR que existiram no sul do país, no estado do Rio Grande do Sul, acerca das quais temos realizado inúmeros estudos (dentre eles WERLE, METZLER, 2009; WERLE et al., 2007). Vale ressaltar que as políticas educacionais dos anos trinta marcam com mais clareza a ação do Estado na educação. A Reforma Francisco Campos articulou o ensino secundário e o superior, criando para este nível de ensino uma demanda. O Manifesto dos Pioneiros de 1932 trouxe demandas de regionalização, planejamento e defesa da escola pública e laica. Na década de 1940 o conjunto das leis orgânicas estrutura nacionalmente os níveis de ensino.

A ENR em funcionamento em vários estados brasileiros nas décadas de 1930, 40 e 50 do século XX tinha como propósito declarado formar professores para a docência em escolas do interior, escolas em geral isoladas, de uma sala de aula e um professor. Há vários estudos que apontam essa finalidade. Um debate amplo focalizando o contexto das propostas de formação de professores primários rurais é feito por Prado (1995; 2000). Miguel (2007) contribui com a análise da experiência paranaense de formação desse professor nas décadas de 1940 a 60. Martins (2000) faz referência aos cursos de regentes do ensino primário do Instituto de Educação do Rio de Janeiro - final 1940 - considerando a cultura escolar, afirmando que tinham como objetivo suprir a carência de professores em regiões rurais (MARTINS, 2000). Souza (1994) descreve a experiência da

\footnotetext{
${ }^{1}$ Trabalho apresentado no X CIHELA, Salamanca, julho 2012, na seção 3 intitulada "La educación superior em Iberoamerica durante la primera mitad del siglo XX (1900-1945)”.
}

escola de Juazeiro, criada em 1934, por acordo de cooperação entre a iniciativa privada do município e o estado do Ceará. Mais recentemente, Farias e Magalhães Júnior (2007) têm discutido essa ENR. A dissertação de Haydée Figueiredo analisa o Curso Normal Rural de Cantagalo, RJ, criado em 1952 (FIGUEIREDO, 1991), já na vigência da Lei Orgânica do Ensino Normal.

Este texto contribui para a compreensão da formação de professores para zonas rurais, demonstrando, principalmente com base em entrevistas com ex-alunos, ex-professores de várias escolas normais rurais do Rio Grande do Sul, que embora os objetivos declarados fossem voltados para a formação do docente de zona rural, seus egressos constituíam um habitus que os guindava a posições de grupo dirigente na sociedade da época. É fundamental a noção de habitus, entendido como a configuração de um esquema de ação, como estruturas incorporadas, gostos formados e consolidados ao longo da vida escolar. Um habitus que emerge no momento da entrevista, entendida como um processo ativo, pois aos entrevistados, como portadores, mobilizados pelo habitus, "basta-lhes ser o que são para ser o que é preciso ser” (BOURDIEU, 1990, p. 24). O autor refere-se ao habitus como coação das condições e dos condicionamentos sociais, até no íntimo do sujeito, como princípio não escolhido de tantas escolhas. O habitus como maneira de ser funciona, no nível prático, como categoria de percepção e apreciação, como princípio organizador da ação (BOURDIEU, 1990, p. 26), intervindo, portanto, nos processos de apropriação, comandando-os, dirigindo-os, selecionando, priorizando, eliminando elementos. É o habitus que proporciona uma espontaneidade que obedece a uma lógica prática, a lógica do fluído, do mais-ou-menos que define a relação cotidiana com o mundo 
(BOURDIEU, 1990, p. 98). São disposições socialmente construídas, que possibilitam ações criadoras, ativas, inventivas de parte dos sujeitos. Portanto, o autor não está falando de um sujeito transcendental, como na tradição idealista (BOURDIEU, 1990, p. 25), mas de sujeitos concretos cujas disposições, na forma de um senso prático, emergem a cada momento. Portanto, o habitus é quase um princípio indelével que emerge inconscientemente, um instrumental disponível inspirador das práticas do sujeito que implica esses dois sentidos de apropriação.

O caráter seletivo da ENR era claro na forma de admissão dos candidatos; uma prova de seleção era exigida aos interessados no curso normal rural. Algumas escolas organizavam um cursinho preparatório para o processo seletivo. Esse cursinho e o exame de admissão subsequente contribuíam para o reconhecimento da qualidade do ensino e indicavam a seletividade de que o ingresso na ENR se revestia. Em alguns casos, a escolha do estabelecimento de ensino era mais por condicionamentos e contingências do que pelas possibilidades que o curso traria e a formação profissional prometida. A relação espacial entre a escola e a residência, assim como o conceito altamente positivo que a instituição gozava na comunidade, entrava nas justificativas de escolha da escola. Por serem escolas de funcionamento integral (internato), o currículo era amplo, exigente. Assim se posicionavam os entrevistados:

"Tinha oito horas de aula, mas aula, não era brincadeira. Tinha que saber a matéria. O colégio era o primeiro da região; o ensino era muito carregado."

Esta forma de ver a escola atraiu alunos das mais variadas partes da região e serviu-lhes de estímulo. A rarefação de estabelecimentos de ensino no interior do Rio
Grande do Sul, a facilidade das ENR oferecerem bolsa de estudos para os alunos estudarem como internos faziam desses estabelecimentos de ensino um espaço disputado de formação. A falta de opções levou muitos jovens à ENR, o que muito ocorria dentre os moradores das redondezas que mantinham filhos na escola na modalidade de alunos semi-internos ou externos:

"Naquela época era a única alternativa que eu tinha de estudar, porque escolas de segundo grau, naquele tempo era primeiro grau, mas depois da quinta série não tinha outra opção na região."

A escola normal era procurada não só por falta de opção, por ser a única escola próxima ou disponível na cidade, mas também pela qualidade do ensino ministrado.

A valorização da escola se justificava, era um estabelecimento que visava à profissionalização de homens para a área da educação por meio de um currículo com ensino teórico e prático aplicados ao campo. Formava indivíduos que valorizavam o estudo e continuaram, em sua grande parte, em outros níveis de ensino, realizando, posteriormente, cursos de ensino médio e superior. Pela disciplina exigente, pela amplitude de formação, pela valorização do ato de estudar e pela qualidade do ensino, as ENR possibilitaram o acesso ao nível superior. Isso, de certa forma, a situa no nível de um ensino secundário com vistas à ascensão ao ensino superior e não apenas como um ensino profissionalizante e complementar ao primário.

Alguns ex-alunos permaneceram no magistério; outros, entretanto, não se fixaram ao meio especialmente pela qualidade da formação e desenvolvimento cientifico e cultural que propiciava. Embora a escola tenha sido criada para formar professores para o meio rural, os exigentes níveis de ensino 
e prática que nela foram desenvolvidos e o tipo de clientela que valorizava o estudo

"Levaram à formação que deu professor, deu advogado, deu médico, deu um monte de coisa que ingressaram na faculdade, com pequenas coisas mais de aperfeiçoamento, entraram na faculdade; foram para Porto Alegre, fizeram o artigo 91 para medicina e tudo passou. São médicos extraviados por aí."

Alguns entrevistados citam colegas que se tornaram juízes, promotores, advogados, que assumiram funções públicas, como militares, como vereadores, prefeitos, professores estaduais, fiscais e superintendentes na Secretaria da Educação, que se tornaram religiosos, padres e bispos. Outros se tornaram diretores de universidade e de colégios reconhecidos pela qualidade de ensino. Pode-se, entretanto, conjeturar que entre algumas famílias havia um certo ethos e um capital cultural que ajudava positivamente frente aos processos de escolarização. $\mathrm{Ou}$ seja, havia um sistema de valores implícitos e interiorizados entre certas famílias e seus filhos, que ajudava a mantê-los na escola. Um entrevistado fala sobre o funcionamento desse ethos de origem familiar, embora focalizando o fazer rural, afirmando que o gosto pelos fazeres agrícolas não era devido ao trabalho da escola, mas decorria de uma certa herança da família:

"Esse gosto pela natureza, pela agricultura, pela pecuária já vem de berço, vem de casa. Eu acho que não nasceu ali na escola."

Em certos casos, a influência materna foi definitiva para a continuidade de estudos. Apesar de terem sido esses os objetivos declarados pela ENR, a instituição deu fundamentação e formação de base suficiente, coerente e relevante, possibilitando uma inserção social e profissional muito ampliada para além dos originais objetivos, o que encaminhou muitos de seus alunos ao ensino superior e a atividades profissionais diferentes e além do magistério rural. O habitus a que a escola contribuiu para formar valorizava o capital cultural e sua acumulação, e não é necessariamente uma adesão fiel, restrita e permanente à docência em escolas rurais e paroquiais. Todavia, conhecimentos e práticas nela adquiridos, relacionados ao mundo agrícola, pontuaram todas as entrevistas, denotando simpatia e preocupação com as questões de desenvolvimento agrícola e zootécnico, uma marca e uma apropriação indelével daqueles que passaram pela Escola Normal Rural. Outro dado significativo decorrente e ao mesmo tempo fortalecedor do bom conceito da escola, este ainda hoje defendido pelos entrevistados, decorre do fato de quanto a escola era procurada, independentemente de sua localização geográfica.

A valorização do nível de ensino da escola e do nível de inserção social, profissional e cultural do aluno e de seus colegas, acrescentada ao respeito que a instituição auferia em nível regional, contribui para reconhecer a importância do ensino recebido e da formação do próprio entrevistado. Um dos entrevistados, entretanto, expressa uma marcante apropriação negativa de vivências na escola, relembrando momentos em que foi injustiçado, foi tratado autoritariamente por professores que desqualificaram o saber prático relacionado à vida rural, ou o ponto de vista do aluno em situações de interação específicas. Os fragmentos de memória desse entrevistado demonstram que não eram toleradas transgressões e que os processos de formação eram fortemente autoritários, na senda da reprodução inquestionável do padrão de comportamento buscado pela comunidade na época.

A perspectiva de ter uma instrução, de ingressar na ENR, era possivelmente uma 
aspiração difundida entre as famílias rurais de poucas posses, mas com aspirações de ascensão. Muitas delas atribuíam à escola um lugar central em seus projetos de futuro. Havia alunos cujas famílias pagavam pelo estudo e outros, filhos de colonos, pequenos agricultores, ou de famílias muito numerosas, que sem a bolsa de estudos do governo do Estado, ou a meia bolsa, não poderiam estudar. Para uma família de zona rural, a dispensa da força de trabalho, de um braço masculino que poderia estar ajudando no cultivo da terra, para que se dedicasse por quatro ou cinco anos aos estudos, indicava valorização da escola e uma expectativa positiva em relação ao trabalho de professor rural.

As famílias que pagavam pelo estudo de seus filhos, ou seja, economicamente estabilizadas, se situavam, possivelmente, como segmento social em ascensão, atribuindo à escola um lugar central em seus projetos de futuro, como define Nogueira (1995, p. 11). Havia o incentivo da família para que o filho continuasse a sua formação para além da escola elementar. $\mathrm{Na}$ época, meu pai achava por bem que cada um tinha que tirar um curso, relata um ex-aluno cuja família residente na localidade em que a escola se situava tinha uma firma de transportes e comercialização de mercadorias para o Rio de Janeiro, São Paulo, Curitiba, Belo Horizonte. Nessa família, embora os filhos tivessem cursado o Normal Rural, nenhum exerceu a profissão de professor rural, pois terminado o curso, trabalhavam na casa comercial do pai. Quando se aposentaram adquiriram terra e começaram a plantar, como que reativando conhecimentos e práticas adquiridos na escola normal. Para esse entrevistado a escola normal era perita em agricultura e isso lhe deu a entender que ele levaria esse conhecimento para a vida inteira.

AspráticaseducacionaisdasENRalmejavam um professor como líder comunitário, religioso e cultural; e, nessa perspectiva se constitui e consolida a ação formativa dessas escolas junto aos normalistas. Ao professor rural cabia executar as tarefas de líder comunitário em todas as dimensões da vida, característica esta muito evidente em vários dos relatos:

\footnotetext{
"Tu chegava numa comunidade tu era o presidente, tu era o padre, tu era o fazedor de enterro [...] a pessoa número um da comunidade era o professor rural; então tinha que saber alguma coisa sobre parto, sobre cuidados com as crianças, com recém-nascidos; o pessoal do interior queria que o professor fosse o técnico do time de futebol."
}

Na ENR a ação comunitária e as tarefas vinculadas à religião não eram ações espontâneas dos alunos, mas organizadas sistematicamente; todos tinham a sua vez de praticar os rituais católicos. O automatismo sobrepunha o ritual ao entendimento dos atos. O importante era saber dizer, era memorizar, decorar palavras; a noção do sentido de cada frase ou etapa do ritual religioso era secundarizada. $\mathrm{O}$ fato de frequentar uma intuição católica não caracterizava a adesão de todos à religião ou a obediência às suas práticas ou aos rígidos métodos disciplinares da escola. A escola, ao mesmo tempo em que formava um líder para o espaço público de comunidades rurais, deixava marcas no indivíduo, consolidando um habitus religioso e de prestação de serviço ao outro.

Estudos históricos referentes à formação do professor rural realizada antes da década de 1940 apontam para uma forte presença da religiosidade na constituição do professor paroquial (KREUTZ, 2004, p. 218). A formação do professor era uma necessidade e uma urgência, pois parte da igreja católica da época identificava a escola publica com o comunismo. O esforço de 
formação de um contingente de professores católicos para a zona rural era no sentido de que os mesmos poderiam atuar como um antídoto contra o comunismo vinculado à disseminação de escolas públicas estaduais.

O processo de formação de professores normalistas rurais inclui-se em uma perspectiva de disseminação de novas práticas de gestão do mundo agrícola, aliado e/ou mobilizado pelas transformações econômicas de época e pelas novas formas de cultivo vislumbradas pelos intelectuais a partir da aplicação do conhecimento científico no mundo rural. Predominava a formação agrícola em relação a aspectos pedagógicos específicos. Depoimentos relacionados a práticas pedagógico-didáticas foram um pouco mais presentes entre ex-professores do que entre ex-alunos, o que reitera a hipótese de que o habitus constituído entre os alunos priorizava a configuração do leigo católico e a cultura agrícola regional, sem uma preocupação centrada na formação de um profissional com prevalentes ou exclusivas competências no domínio didático-pedagógico. Nesse sentido, a formação de um grupo de profissionais capazes de disseminar novas perspectivas e tecnologias agrícolas era um dos objetivos da Escola Normal Rural percebido e apropriado por seus alunos, pois os entrevistados referem-se, insistentemente, à formação, às práticas e estudos voltados para a prática rural, o que é, inclusive, articulado por eles com orgulho. Era um currículo denso, nós tínhamos na época quatorze matérias.

Os depoimentos evidenciam um olhar, um foco de atenção, uma avaliação acerca de elementos que compunham sua vida escolar - religião, esporte, estudo, agricultura, atividades, práticas, ritos, normas - sem destaque a um pano de fundo, a um horizonte mais amplo circundante. Entretanto, no período, o estado pretendia que a educação atuasse no enfrentamento de problemas de segurança nacional, política demográfica e colonização interna, conforme afirma Prado (1995). Esses aspectos e suas consequências não foram considerados pelos entrevistados. Entretanto, pode-se dizer que a ENR em que os entrevistados constituíram parte de sua vida escolar cumpriu os fins como instituição educacional adaptada ao seu tempo e adaptadora daqueles que por ela passavam. Para as políticas educacionais da época, a ENR deveria formar o professor para a escola elementar rural de forma que atuasse como líder político, intelectual, educacional, com conhecimentos suficientes para as atividades agrícolas, um tipo de mão-de-obra especializada para o campo. Muitos dos formados em ENR não atuaram no magistério rural, ou apenas em escolas rurais, o que não significa que as propostas da instituição tenham sido apropriadas pelos que nela estudavam. Sua passagem pela ENR configurou uma formação ampla, possibilitando-lhes diferentes perspectivas de vida, atuação em áreas profissionais diversas, visto que o conjunto de conhecimentos adquiridos os potencializava para inúmeros caminhos de vida e para assumirem oportunidades que emergiam. A formação das ENR propiciou o surgimento de uma elite comunitária intelectualizada, pautando seu modo de vida em processos técnico-científicos. Um grupo de líderes, embora nem todos permanecessem na prática do magistério rural. As ENR foram instituições que aliaram o desejo de um segmento social com o novo ethos requerido pela conjuntura social. Os processos, as condutas escolares, as formas de organização indicam que o capital cultural transmitido pela ENR visava à formação de uma elite rural/comunitária capaz de causar impacto - a partir da escola rural - nas formas de vida e nas tecnologias utilizadas nas práticas de cultivo agrícola. 


\section{Referências}

ALMEIDA, J. R. P. História da instrução pública no Brasil (1500 - 1889). São Paulo: EDUC; Brasília: MEC/INEP, 1989.

BOURDIEU, P. Coisas ditas. São Paulo: Brasiliense,1990.

Questões de sociologia. Rio de Janeiro: Marco Zero, 1983.

FIGUEIREDO, H. G. F. Curso normal rural de Cantagalo: uma experiência fluminense na história da formação de professores primários. Dissertação (Mestrado em Educação). Rio de Janeiro: PUCRJ, 1991.

KREUTZ, L. O professor paroquial: magistério e imigração alemã. Pelotas: Seiva, 2004.

MARTINS, A. M. Os anos dourados e a formação do professor primário no Instituto de Educação do Rio de Janeiro (1945 - 1960). Teias - Revista da Faculdade de Educação da UERJ, Rio de Janeiro, n.1, p. 56 - 65, 2000.

NOGUEIRA, M. A. Famílias de camadas médias e a escola: bases preliminares para um objeto em construção. Educação e Realidade, v.20, n.1, p.9-25. jan./jun. 1995.

PRADO, A. A. Educação no Estado Novo (1937 - 1945): o debate sobre a formação do professor primário rural. Teias - Revista da Faculdade de Educação da UERJ, n.1, p. 46 - 55, 2000.

PRADO, A. A. Ruralismo pedagógico no Brasil no Estado Novo. Estudos, Sociedade e Agricultura. v.4, p. 5-27, 1995.

WERLE, F. Escola complementar como espaço de formação. Veritas, Porto Alegre, v.42, n.2, p. 307 - 316, 1997.

WERLE, F.; THUM, C.; MARTINSON, C. C.; TRINCHÃO, G. Escola Normal Rural
La Salle na Voz dos Ex-alunos. In: Werle, F. (Org.). Educação rural em perspectiva internacional. Ijuí, RS: UNIJUÍ, 2007.

Recebido em: 26/07/2012

Aceito em: 06/08/2012 